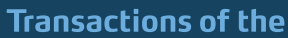

\section{A NOTE ON VOICING ALTERNATION IN THE TIBETAN VERBAL SYSTEM}

\author{
By Nathan W. HiLl \\ School of Oriental and African Studies, University of London
}

\begin{abstract}
A recent paper on the prehistory of the Tibetan verbal system by Guillaume Jacques (2012), in keeping with many previous authorities, presents Tibetan verbs as occurring in pairs, with a voiced intransitive and a voice-alternating transitive member. However, as noticed by Uray, Tibetan verbs occur in triplets with no relationship between voicing and transitivity.
\end{abstract}

Many authors have observed that verbs exhibiting voicing alternation, such as $h b o, p o s, d b o$, pos 'pour', ${ }^{1}$ frequently have a corresponding intransitive verb with voiced initial, in this case $h b o, b o$ 'overflow', with both verbs appearing to derive from the same root. ${ }^{2}$ Conrady (1896: 27) associates the voiced members of the transitive paradigm with the voiced intransitive paradigm. This idea has proven tenacious. ${ }^{3}$ Thus, LaPolla (2003: 23) writes that 'for the verb "put off, pull of, take off", we have present hbud-pa and future $d b u d$, which derive from an intransitive stem *bud, and perfect and imperative $p u d$, which derives from a transitive stem *pud'. The claim that the voiced members of the alternating paradigm are somehow intransitive is easily dismissed; the verb hbud, pud, dbud, pud 'take off' is transitive; the suggestion that certain of its stems are intransitive is unmotivated by any syntactic or semantic considerations. LaPolla's suggestion is tantamount to positing 'take' as transitive but 'took' intransitive.

Jacques (2012: 215) intelligently rejects the association of the voiced member of the transitive paradigm with the intransitive paradigm, but still characterises voicing alternation as primarily an opposition between a voiced intransitive verb and a voice-alternating transitive verb. ${ }^{4}$ This characterisation is insufficient. As Uray (1953: 50-1) notes, voicing alternation occurs among triplets and not pairs of verbs. A voiced intransitive (A), voicealternating transitive (B), and voiceless intransitive (C) all derive from the same root. This

${ }^{1}$ Here I use the Library of Congress transliteration system, except that I omit aspiration since it is subphonemic (cf. Hill 2007) and I use 'h’ rather than an apostrophe for the twenty-third letter of the Tibetan alphabet. All verb paradigms are taken from Hill (2010).

2 The characterisation of Tibetan verbs as 'transitive' or 'intransitive' is here as always based on the authority of the dictionaries or the transitivity of the translation equivalent in a western European language. What is meant by these terms, and whether these verbs actually conform to such characterisation, has never been researched. In employing Tibetan sources Hill (2010) takes ta dad pa 'different' and bya hbrel las tsig 'action connected verb' as equivalent to 'transitive' and ta mi dad pa 'indifferent' and bya med las tsig 'action unconnected verb' as equivalent to 'intransitive' (cf. Hill 2004: 85-6).

3 Another tenacious idea of Conrady's (1896) is the association of the Tibetan $s$ - prefix causative with voicing alternation. LaPolla (2003: 23-4) and Jacques (2012: 215, note 7) rightly reject this association; voicing alternation and $s$ - prefixation are quite separate phenomena both in Tibetan and Rgyalrong. Nonetheless, Mei (2012) continues to credit all causative phenomena in Tibeto-Burman languages with an $s$ - prefix.

${ }^{4}$ In Jacques's (2012: 215) words, 'typically, the intransitive paradigm has a voiced initial, while its transitive counterpart has an unvoiced initial in the past and imperative stems and a voiced initial in the present and future stems'. 
observation of Uray's has been consistently ignored in Tibetan grammars and handbooks (e.g. Beyer 1992; Gyurme 1992; Schwieger 2006) as well as in the Tibeto-Burman literature (e.g. LaPolla 2003). The voiceless intransitive appears to derive from the present stem of the voice-alternating transitive. Features peculiar to the present stem of the voice alternating transitive (such as an 'a' to 'e' ablaut, $-d$ suffix, and epenthetic dental infix) are preserved in stems of the voiceless member as part of the root (cf. Beyer 1992: 113).

(1) a. A: $\sqrt{g a g}(h \mathrm{gag}, h \mathrm{~g} a g s)$ 'be stopped, break off'

B: Vgag (hgog/hgegs, bkag, dgag, kog) 'hinder, prohibit'

C: $\sqrt{\text { kegs }(k e g s, k e g s)}$ 'be hindered, be prohibited'

b. A: Vgan $(g a \dot{n}, g a \dot{n})$ 'fill intr.'

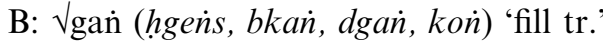

$\mathrm{C}$ : $\sqrt{\mathrm{ken} s}$ (kenss, kenss) 'be full'

c. A: لVgab ( $g a b, g a b, g a b, g o b)$ 'hide intr.'

B: Vgab (hgebs, bkab, dgab, kob) 'cover tr.'

C: $\sqrt{\text { kebs }(k e b s, k e b s)}$ 'be covered over'

d. A: لVgrol (hgrol, grold) 'be free'

B: لVrol (hgrol, bkrold, dgrol, krold) 'liberate'

C: $\sqrt{\mathrm{krol}}($ hkrol, krol) 'unravel'

e. A: $\sqrt{ } \mathrm{dul}(d u l$, duld $)$ 'be tame'

B: Vdul (hdul, btul, gdul, tul) 'tame, subdue'

C: Vtul (htul, tul) 'be tame'

f. A: $\sqrt{\text { zug }(z u g, z u g s)}$ 'pierce, penetrate'

B: Vzug (hdzugs, btsugs, gzugs, tsugs) 'plant, establish, insert'

C: Vtsugs (htsugs, tsugs) 'go into, begin'

In some cases only two of the three variants are extant. Thus, in the type noted by Conrady (1896), LaPolla (2003) and Jacques (2012) there is a voiced intransitive, and voice alternating transitive, but no evidence for a voiceless intransitive verb.

(2) a. A: لVum (hgum, gum) 'die'

B: Vgum (hgums, bkums, dgum, kums) 'kill'

$\mathrm{C}:-$

b. A: Vbab (hbab, babs) 'fall, descend'

B: $\sqrt{ }$ bab (hbebs, pab, dbab, pob) 'bring down'

C: -

c. A: $\sqrt{\text { byun }}($ hbyuñ, byun்) 'come out, appear'

B: $\sqrt{ }$ byun (hbyin, pyun், dbyun், pyunis) 'take out, remove'

$\mathrm{C}:-$

d. A: $\sqrt{ }$ bye (hbye, bye) 'open intr.'

B: Vbye (hbyed, pye, dbye, pyes) 'open tr.'

$\mathrm{C}:-$

e. A: Vbral (hbral, bral) 'separate intr.'

B: Vbral (hbral, pral, dbral, prol) 'separate tr.'

C: -5

f. A: Vbri (hbri, bri) 'lessen, diminish'

B: Vbri (hbrid, pris, dbri, pris) 'reduce, subtract'

C: -

${ }^{5}$ There may be evidence for a type (C); some lexica give hpral and prel as stems of the type (B) verb. 
In other cases the voice alternating transitive (B) and the voiceless intransitive (C) are attested whereas the voiced intransitive (A) is missing.

(3) a. A: -

B: Vgug (hgugs, bkug, dgug, kug) 'summon'

$\mathrm{C}: \sqrt{\mathrm{kug}}(\mathrm{kug}, \mathrm{kugs})$ 'get, find'

b. A: -

B: Vgod (hgod, bkod, dgod, kod) 'place, register'

C: $\sqrt{k o d}(h k o d, h k o d)$ 'be situated, be registered'

c. A: -

B: $\sqrt{\text { don }}($ hdon, bton, gdon, ton) 'take out'

C: Vton (hton, tond) 'go out, come out'

d. A: -

B: Jjun (hjun, bcun, gcun, ${ }^{6}$ cun) 'tame, subdue'

C: V Vun (hcun, cun) 'be tamed, be subdued'

e. A: -

B: Vdzud (hdzud, btsud, gzud, tsud) 'put inside'

C: Vtsud (htsud, tsud) 'be put inside'

Finally, there are cases where the voiced intransitive (A) and voiceless intransitive (C) are attested, but a voice alternating transitive verb does not occur.

(4) a. A: Vgrig (hgrig, hgrig) 'suit, agree'

B: -

C: $\sqrt{ }$ krig (hkrig, hkrigs) 'cohere, stick together'

b. A: Vgril (hgril, gril) 'be twisted'

B: -

C: $\sqrt{ }$ kril (hkril, hkkrild) 'wind, coil'

c. A: $\sqrt{ } \mathrm{du}(h d u, h d u s)$ 'come together, assemble'

B: -

C: Vtu $(h t u, h t u)$ 'gather, collect'

This pattern of verb triplets makes clear that there is no overall relationship between voicing and transitivity in Tibetan. Both voiceless and voiced intransitive verbs derive from the same root. Investigations of the origin of voicing alternation in Tibetan, such as Jacques (2012), must explain the alternation among all three members of triplets and not simply ignore one of the three.

Department of China and Inner Asia and Department of Linguistics

School of Oriental and African Studies, University of London

Thornhaugh Street

Russell Square, London WC1H OXG, UK

Email:nh36@soas.ac.uk

\section{REFERENCES}

Beyer, Stephen, 1992. The Classical Tibetan language, New York: State University of New York. Bsam gtan, 1979. Dag yig gsar bsgrigs, Xining: Mtsho snon mi rigs dpe skrun khan. 
Conrady, August, 1896. Eine Indochinesische Causativ-Denominativ-Bildung und ihr Zusammenhang mit den Tonaccenten, Leipzig: O. Harrassowitz.

Das, Sarat Chandra, 1902. A Tibetan English Dictionary with Sanskrit Synonyms, Calcutta: Bengal Secretariat Book Depôt.

Gyurme, Kesang, 1992. Le Clair Miroir: Enseignement de la Grammaire Tibétaine, Arvillard: Editions Prajñā.

Hill, Nathan W., 2004. 'Compte rendu: review of Paul G. Hackett, A Tibetan Verb Lexicon. Ithaca: Snow Lion, 2003', Revue d'Etudes Tibétaines 6, 78-98.

Hill, Nathan W., 2007. 'Aspirate and non-aspirate voiceless consonants in Old Tibetan', Language and Linguistics 8 , 471-93.

Hill, Nathan W., 2010. A Lexicon of Tibetan Verb Stems as Reported by the Grammatical Tradition, Munich: Bayerische Akademie der Wissenschaften.

Jacques, Guillaume, 2012. 'An internal reconstruction of Tibetan stem alternations', Transactions of the Philological Society 110, 212-24.

LaPolla, Randy J., 2003. 'Overview of Sino-Tibetan morphosyntax', in Graham Thurgood \& Randy J. LaPolla (eds.), The Sino-Tibetan Languages, London: Routledge, 22-42.

Mei, Tsu-Lin, 2012. 'The causative *s- and nominalizing $*_{-s}$ in Old Chinese and related matters in ProtoSino-Tibetan', Language and Linguistics 13, 1-28.

Schwieger, Peter, 2006. Handbuch zur Grammatik der klassischen tibetischen Schriftsprache, Halle: International Institute for Tibetan and Buddhist Studies.

UrAy, GÉZA, 1953. 'Some problems of the ancient Tibetan verbal morphology: methodological observations on recent studies', Acta Linguistica Academiae Scientiarum Hungaricae 3, 37-62. 